\title{
DESENVOLVIMENTO LOCAL E CONSERVAÇÃO DOS RECURSOS NATURAIS NO PARQUE NACIONAL DO IGUAÇU E ENTORNO
}

\author{
Local Development and Natural Resources Conservation: \\ The Iguaçu National Park and the Surrounding Communities
}

\author{
Msc. Fabiana Faxina \\ Universidade Estadual de Santa Cruz \\ Campus Soane Nazaré de Andrade, km 16 Rodovia Ilhéus-Itabuna, CEP: 45662-900, Ilhéus (BA) Brasil \\ Tel.: (+ 55 73) 36805144 - Email: fabi_fa@hotmail.com \\ Prof. Dr. Salvador Dal Pozzo Trevizan \\ Universidade Estadual de Santa Cruz \\ salvador@uesc.br \\ Prof. Dr. Paulo Cesar Pontes Fraga \\ Universidade Federal de Juiz de Fora \\ pcp_fraga@yahoo.com.br
}

\section{aaCaa}

\begin{abstract}
Resumo
O presente estudo busca identificar os principais resultados do Programa de Desenvolvimento do Turismo Sustentável no Entorno do Parque Nacional do Iguaçu no que se refere às melhorias socioeconômicas auferidas por seus beneficiários, bem como, analisar como eles se posicionam diante das questões ambientais, tendo em vista ações desenvolvidas pelo referido programa. O trabalho teve como área de estudo o Parque Nacional do Iguaçu e dois dos seus municípios de entorno: Capanema e Serranópolis do Iguaçu, todos no Estado do Paraná. Com a análise dos dados foi possível observar aspectos positivos tanto para o Parque quanto para a comunidade do entorno. Ganhos econômicos e geração de emprego no campo foram resultados expressivos para os beneficiários. Em contrapartida, os mesmos assumiram práticas ambientalmente menos impactantes, o que é expressivo para o Parque, que também obteve melhoria da sua imagem político-institucional.
\end{abstract}

Palavras-chave: Unidade de conservação, Comunidade de entorno, Desenvolvimento local.

\begin{abstract}
This paper presents socio-environmental impacts originated from a Sustainable Tourism Development Program, in the surrounding areas of the Iguacu National Park (INP), in Brazil. Social-economic improvements for the beneficiaries of the Program, and behavioral changes regarding environmental issues due to actions undertaken by the Program will be taken into consideration. Documentary and fieldwork research were conducted for data collection at the INP and in two of its surrounding municipalities - Capanema and Serranópolis do Iguaçu - at the state of Parana. Findings show positive aspects for both, the Park and communities around it. Economic gains and non-farm job for members of the family farm owner, on the field side, were identified. On their side, beneficiaries have moved to less aggressive behavior over natural resources of the Park, along with improving its political and institutional image.
\end{abstract}

Key words: Conservation area, Surrounding community, Local development.

\section{Resumen}

El presente estudio pretende identificar los principales resultados del Programa para el desarrollo del turismo sostenible en los alrededores del Parque Nacional Iguazú en relación a mejoras socioeconómicas obtenidos por los beneficiarios, así como analizar la manera en que se sitúan delante de las cuestiones ambientales con miras las acciones desarrolladas por este programa. El trabajo tuvo el área de estudio el Parque Nacional de Iguazú y sus dos municipios del entorno: Capanema y Serranópolis de Iguaçu, todos en el estado de Paraná. Con el análisis de los datos fue posible observar aspectos positivos tanto para el Parque y a la comunidad de los alrededores. Beneficios económicos y generación de empleo en el campo fueron lós resultados mas destacados para los beneficiarios. Estos, por otro lado, asume prácticas ambientalmente menos impactantes, que es expresivo por el Parque, que también ha mejorado su imagen político-institucional. Palabras clave: unidad de conservación, comunidad del entorno, el desarrollo local.

Palabras clave: Razón comunicativa, afluencia, transdisciplinariedad.

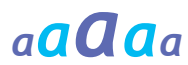

Revista da ANPEGE, v. 7, n. 8, p. 107-118, ago./dez. 2011.

ISSN 1679-768 X @ (2003, Associação Nacional de Pesquisa e Pós-Graduação em Geografia. Todos os direitos reservados. 


\section{INTRODUÇÃO}

A política de criação de unidades de conservação (UC) origina-se do pressuposto de que a alteração e a domesticação da biosfera pelo ser humano é um processo inevitável e, para evitar a perda total das espécies, faz-se necessário conservar pedaços do mundo natural em seu estado primitivo, antes que a intervenção humana as destrua (ARRUDA, 2000). Assim, pode-se argumentar que a criação de unidades de conservação remete a uma visão conservacionista na qual o homem é visto como agente destruidor deste meio.

No Brasil, a ideia inicial de criação de parques nacionais partiu de André Rebouças, em 1876 (apud PÁDUA, 2004). Na época, Rebouças publicou um artigo intitulado "Parque Nacional", onde indicava a criação de dois parques: um localizado na Ilha do Bananal e o outro no Paraná, que se estenderia das Sete Quedas (submersas pelo Lago da Hidroelétrica de Itaipu, entre Guaíra, no Paraná e Mundo Novo, no Mato Grosso do Sul) até o município de Foz do Iguaçu.

Inicialmente, a criação de parques nacionais, no Brasil, não estava ligada à conservação, mas ao resguardo de belezas cênicas. Esta tendência mudou a partir dos anos 1960, quando o país começou a alargar suas fronteiras agrícolas e expandir a urbanização (MORSELLO, 2006). Passou-se, então, a criar áreas protegidas para a conservação, contrapondo a transformação dos ambientes naturais.

No que se refere à população local, a política de seleção de unidades de conservação, segundo Morsello (2006), teria se caracterizado como ato de negligência, pois os conflitos entre ambas perduram até hoje no Brasil. É conhecido que o Sistema Nacional de Unidades de Conservação da Natureza (SNUC) não permite a presença do ser humano na condição de residente das unidades pertencentes ao grupo de proteção integral, cujo objetivo é preservar a natureza, permitindo uso indireto dos recursos naturais, exceto nos casos previstos na Lei. Neste grupo, entre outras, encontra-se a categoria Parque Nacional, cujos objetivos, conforme artigo $11^{\circ}$. do SNUC, são de "preservação de ecossistemas naturais de grande relevância ecológica e beleza cênica, (...) realização de pesquisas científicas e o desenvolvimento de atividades de educação e interpretação ambiental, de recreação em contato com a natureza e de turismo ecológico". Por outro lado, o grupo de uso sustentável compatibiliza a conservação da natureza com o uso sustentável dos recursos naturais. Hoje, os critérios estabelecidos pelo Ministério do Meio Ambiente (MMA) para criação de unidades de conservação estão pautados nas indicações de regiões prioritárias para a conservação da biodiversidade e em áreas com maior risco de pressão antrópica, o que antes era feito em regiões de menor complexidade social e política (MMA, 2007). Assim, inevitavelmente, a criação de unidades de conservação não deixa de ser um mecanismo de restringir no presente o acesso a determinados ambientes.

Conforme Pimbert e Pretty (2000), a degradação se torna mais provável quando as comunidades locais são excluídas dos processos de criação de áreas protegidas, destacando que as populações rurais e nativas possuem critérios, enquanto gestores de sistemas complexos, para o manejo das áreas naturais, indo além do que os cientistas da conservação, numa perspectiva reducionista da questão ambiental, orientam para tais áreas.

Essa exclusão social leva à pressão sobre os elementos naturais para suprir parcialmente as necessidades de sobrevivência. Até recentemente, tem-se observado um distanciamento entre a política sobre UC e os pressupostos para se desencadear o processo de desenvolvimento em comunidades locais, fazendo com que estas vivessem em conflito com a política de conservação da biodiversidade. Arruda (1999) aponta a existência de uma visão reformulada da interpretação inicial dos conflitos entre áreas naturais e populações locais, em busca de uma compreensão mais precisa destas populações, de seu padrão de ocupação do espaço e utilização dos recursos naturais. No Brasil, a Reserva Extrativista é um exemplo de categoria de UC cujos objetivos, de acordo com o SNUC, se concentram na proteção dos meios e culturas das populações tradicionais, assegurando o uso sustentável dos recursos naturais contidos nesta UC, conciliando, então, a permanência de populações humanas.

Torna-se cada vez mais evidente que a dissociação entre a política de criação de UCs e as necessidades humanas, no interior ou no entorno destas unidades, tem produzido efeitos negativos para 
a integridade da biodiversidade, requerendo uma conciliação entre tais necessidades e os objetivos de resguardar os elementos naturais. Segundo Borrini-Feyerabend, Kothari e Oviedo (2004), os objetivos atuais resultantes dessa interação entre áreas protegidas e populações humanas incluem a utilização sustentável dos recursos naturais, a preservação do ecossistema, a integração do amplo processo de desenvolvimento social junto ao papel central de conservação da biodiversidade. Deste conjunto resulta o respeito aos valores culturais como essencial à biodiversidade e a necessidade de se envolver as comunidades locais na gestão destas áreas.

O debate agora é voltado para a questão social, não só no desenvolvimento das comunidades locais, mas também na inserção das mesmas como parceiras nos processos de decisão e manejo das áreas protegidas. Como falar em proteção dos elementos naturais nos casos em que pessoas se enquadram em condições socioeconômicas que não lhes permitem o acesso ao mínimo necessário para a própria sobrevivência? Como conduzir para o entendimento da importância de criação de áreas protegidas, diminuindo os conflitos socioambientais, proporcionando melhoria na qualidade de vida das populações locais e assegurando melhoria da proteção dos elementos naturais?

De acordo com Lopes (2006, p. 34-36), nesses casos, deve existir a ambientalização dos conflitos sociais, referindo-se à "construção de uma nova questão social, uma nova questão pública (...) [e que] implica simultaneamente transformações no Estado e no comportamento das pessoas (no trabalho, na vida cotidiana, no lazer)". Tais transformações, para o autor, estão relacionadas a fatos como a importância institucional do meio ambiente dos anos 1970 até os dias atuais, os conflitos sociais locais e como estes interferem na adoção de novas práticas, ou seja, a educação ambiental, a participação e a questão ambiental como "nova fonte de legitimidade e de argumentação nos conflitos".

Assim, a participação torna-se requisito fundamental para desencadear um processo de desenvolvimento local sustentável na gestão dos recursos naturais e culturais existentes numa localidade.

A necessidade da participação na gestão das áreas protegidas, de os organismos de conservação se relacionar com as pessoas, influenciando a opinião pública, demonstrando que é possível conciliar o desenvolvimento com a proteção ambiental, por meio da participação das comunidades e apresentando os benefícios que estas áreas podem trazer, tem sido insistentemente debatido em Congressos Mundiais de Parques Nacionais e Áreas Protegidas. Tem-se evidenciado que casos de gestão compartilhada já resultaram num bom rendimento da conservação da biodiversidade, melhorando a relação entre área protegida e populações locais (UICN, 2008).

Bensusan (2006) observa que no cenário internacional atual é evidente a preocupação com as comunidades locais no que se refere à conservação do meio natural em áreas protegidas. Murray Li (2002), por sua vez, argumenta que a gestão de recursos naturais a partir da comunidade oferece a melhor perspectiva para se atingir os objetivos de conservação ao mesmo tempo em que melhora as condições de vida das comunidades rurais pobres, às quais têm sido negados os direitos fundamentais de participarem nas decisões que refletem em suas vidas. A sustentabilidade de florestas tropicais, no dizer de Hartshorn (1995), deve integrar conservação e desenvolvimento.

Neste particular, o ecoturismo bem conduzido apresenta potencialidades singulares para a conservação do meio ambiente de forma harmoniosa com o bem estar das populações. Segundo Goodwin (2002), há muito tempo já tem sido reconhecido o potencial do turismo na contribuição para cobrir custos de conservação e promover oportunidades econômicas para as comunidades que vivem nas adjacências de patrimônios naturais. Segundo Ceballos-Lascuráin (1996, p.32), na medida em que as UCs incorporam um ou vários componentes do desenvolvimento, elas se tornam meios para o desenvolvimento sustentável. Para ele, um dos impactos do turismo com base no entorno de parques nacionais é a redução do fluxo migratório, em função das oportunidades de emprego e renda resultantes dessa atividade.

Para abordar resultados efetivos de ações empreendidas a partir dessa nova perspectiva na relação entre UC e comunidades locais, esta pesquisa tomou como base empírica o PDTS, de- 
senvolvido no entorno do Parque Nacional do Iguaçu (PNI), a partir do ano de 2004. Procurou-se identificar os ganhos em termos econômicos, sociais e comportamentais para os beneficiários do Programa, e ganhos em conservação dos recursos naturais, resultantes de ações do PDTS, tendo como pressuposto que estes ganhos em favor das comunidades refletem positivamente na conservação do Parque. Especificamente, buscou-se: identificar as principais melhorias socioeconômicas que os beneficiários obtiveram após aderirem às ações do PDTS e analisar a relação da comunidade do entorno com questões ambientais, decorrentes das ações desenvolvidas pelo referido Programa, bem como os riscos que as comunidades representam para o Parque após as mudanças observadas.

\section{O PDTS E A ÁREA DA PESQUISA}

Mesmo sendo um dos primeiros parques nacionais criado no Brasil, ações envolvendo a comunidade do entorno do PNI são observadas apenas a partir do ano de 2000, por meio de educação ambiental, e quatro anos depois com a implementação do Programa de Desenvolvimento do Turismo Sustentável (PDTS). Trata-se de ações que se configuram como oportunidades de aproximação, favorecendo o diálogo no sentido de proporcionar à comunidade melhor entendimento acerca da $\mathrm{UC}$, bem como fortalecer a imagem institucional desta última, na busca da compatibilização dos interesses de ambas as partes.

O PDTS foi implementado como iniciativa da parceria do Instituto Brasileiro do Meio Ambiente e dos Recursos Naturais Renováveis (IBAMA) com o Serviço Social Autônomo Ecoparaná, trazendo os segmentos de turismo rural e turismo ecológico como alternativas de desenvolvimento e proteção da área periférica desta UC. Os interesses pelo Programa se originaram em 2003, quando havia uma motivação, por parte da gestão do Parque, para a elaboração de projetos voltados para a área de entorno que proporcionassem melhor interação com as comunidades, iniciando-se, então, os diálogos com estas populações.

A administração do Parque identificou o turismo como um segmento da atividade econômica que pudesse ser desenvolvido de modo ordenado, acarretando impactos negativos pouco expressivos para o meio ambiente, mas que, todavia, pudesse proporcionar geração de emprego e renda. Outro motivador foi o fato de que o incentivo ao desenvolvimento do turismo nos municípios do entorno já estava previsto no plano de manejo. Optou-se pela participação da comunidade nos processos decisórios e o seu início ocorreria em 2003. Neste mesmo ano houve a reincidência de movimentação da população contra o fechamento da Estrada do Colono. Esta estrada, com $18 \mathrm{Km}$ de extensão, atravessa o Parque e liga os municípios de Serranópolis do Iguaçu e Capanema. A proibição do seu uso, prevista no plano de manejo da UC, tem sido motivo de conflito histórico entre esta e seu entorno, já que o outro meio de se chegar de um município ao outro é contornando o Parque pelas rodovias BR 277 e BR 163, ampliando o percurso de 18 para $140 \mathrm{~km}$.

A proibição, que gera o conflito, possui base científica para seus argumentos e está em consonância com os objetivos e com a regulamentação da categoria Parque Nacional, prevista no SNUC. Já o funcionamento da Estrada favorece o acesso da população de um município a outro, ao encurtar consideravelmente a distância, além da relação cultural, pois durante décadas a Estrada era tida como rota para visitas entre membros da mesma família. Em função do ressurgimento do conflito, com manifestações da população a favor da reabertura da Estrada, os trabalhos do PDTS foram retomados no início de 2004.

A parceria para a realização do programa foi estabelecida entre as três esferas públicas de governo, representadas pelo IBAMA, em nível federal, pela Ecoparaná, em nível estadual, e pelas prefeituras municipais do entorno. Estas últimas assumiam o papel de facilitadoras no contato com os atores locais, que comporiam o público diretamente abrangido pelo Programa.

No período entre o final do ano de 2007 e início de 2008 foram desenvolvidas as últimas ações do PDTS nos municípios. Nesta época os trabalhos se concentravam em Capanema e Serranópolis do Iguaçu. A partir daí, os municípios deveriam prosseguir com as ações, buscando eles mesmos suas próprias parcerias. 
Capanema é margeado pelo rio Iguaçu e, na sequência, pela mata densa do Parque. O município se caracteriza pela produção orgânica e incentiva a agricultura familiar. No final de 2005, foi criada a Associação de Turismo Doce Iguassu, sociedade civil, sem fins lucrativos e com objetivos de contribuir para a melhoria da qualidade de vida dos associados, como resultado da organização da atividade turística, valorizando esta atividade, resgatando a identidade cultural, sensibilizando a população local quanto ao potencial turístico do município e divulgando o roteiro de turismo rural Doce Iguassu. Eventos marcantes se efetivaram um ano depois, como: a) Criação do Departamento Municipal de Turismo, o qual estabeleceria uma parceria com o PDTS no município; b) Inserção do município no Programa Nacional de Regionalização do Turismo; c) Lançamento do roteiro de Turismo Rural Doce Iguaçu.

No ano de 2008, parte do entusiasmo do município e dos produtores rurais ficou arrefecida em função da crise financeira do PDTS. No ano seguinte, na tentativa de retomar os trabalhos, o município buscou parceria com o Serviço Brasileiro de Apoio às Micros e Pequenas Empresas (SEBRAE).

Serranópolis do Iguaçu começou a estruturar a sua atividade turística com o início do PDTS. A Secretaria de Indústria e Comércio foi incumbida de atuar junto ao PDTS, fazendo parceria também com o Instituto Paranaense de Assistência Técnica e Extensão Rural (EMATER - Paraná). A agroindústria, que já era uma atividade desenvolvida no município, foi incorporada nas ações que o Programa abarcaria. Foram convidados produtores rurais que tinham algum potencial na propriedade ou que tivessem interesse em desenvolver atividades relacionadas à agricultura familiar, equipamentos de lazer e hospedagem, entre outros. Não existia, na ocasião, uma associação formal dos envolvidos com o turismo rural no município, mas já haviam ocorridas algumas reuniões para que a mesma fosse estruturada.

\section{PROCEDIMENTOS METODOLÓGICOS}

Como base empírica, foram selecionados os municípios de Capanema e Serranópolis do Iguaçu - duas comunidades do entorno do PNI - por apresentarem uma particularidade em relação aos demais municípios que compõem o entorno Parque: situam-se em extremidades, sul e norte da unidade, respectivamente, onde se localiza a antiga Estrada do Colono que atravessava o Parque (Figura 1), tendo sido objeto de freqüentes conflitos entre esta UC e as comunidades, como anteriormente citado. Neste sentido, a escolha destes municípios também foi motivada para observar se tal conflito ainda se evidenciaria após as ações do PDTS. Outros fatores que levaram à escolha destes municípios relacionaram-se às atividades turísticas neles desenvolvidas e ao avanço das ações do PDTS.

Inicialmente, visitou-se o Parque durante o mês de julho de 2008 a fim de coletar informações e analisar documentos necessários para a formatação do projeto de pesquisa. Nesta fase, foram obtidos depoimentos verbais de pessoas da administração, envolvidas com o PDTS. Numa segunda visita, foram coletados os dados da pesquisa, utilizando-se entrevista semi-estruturada que, segundo Denker (2000, p. 137-138), se caracteriza como "uma comunicação verbal entre duas ou mais pessoas, com um grau de estruturação previamente definido, cuja finalidade é a obtenção de informações de pesquisa e de novas consultas documentais". Esta técnica, segundo a autora, "permite maior liberdade do pesquisador", podendo ocorrer adição de perguntas não previstas, a depender do desenrolar das respostas emitidas pelos entrevistados às perguntas formuladas.

Utilizou-se a análise de conteúdo que, segundo Bardin (1972) e Minayo (2004), consiste numa técnica de avaliação de comunicações, descrevendo de forma sistemática e objetiva os conteúdos de mensagens que permitem a inferência de conhecimentos relativos a elas. Procede-se analisando o conteúdo temático de uma comunicação que tenha algum significado para o objetivo que se busca. A presença de determinados temas denota os valores de referência e modelos comportamentais presentes no discurso. 


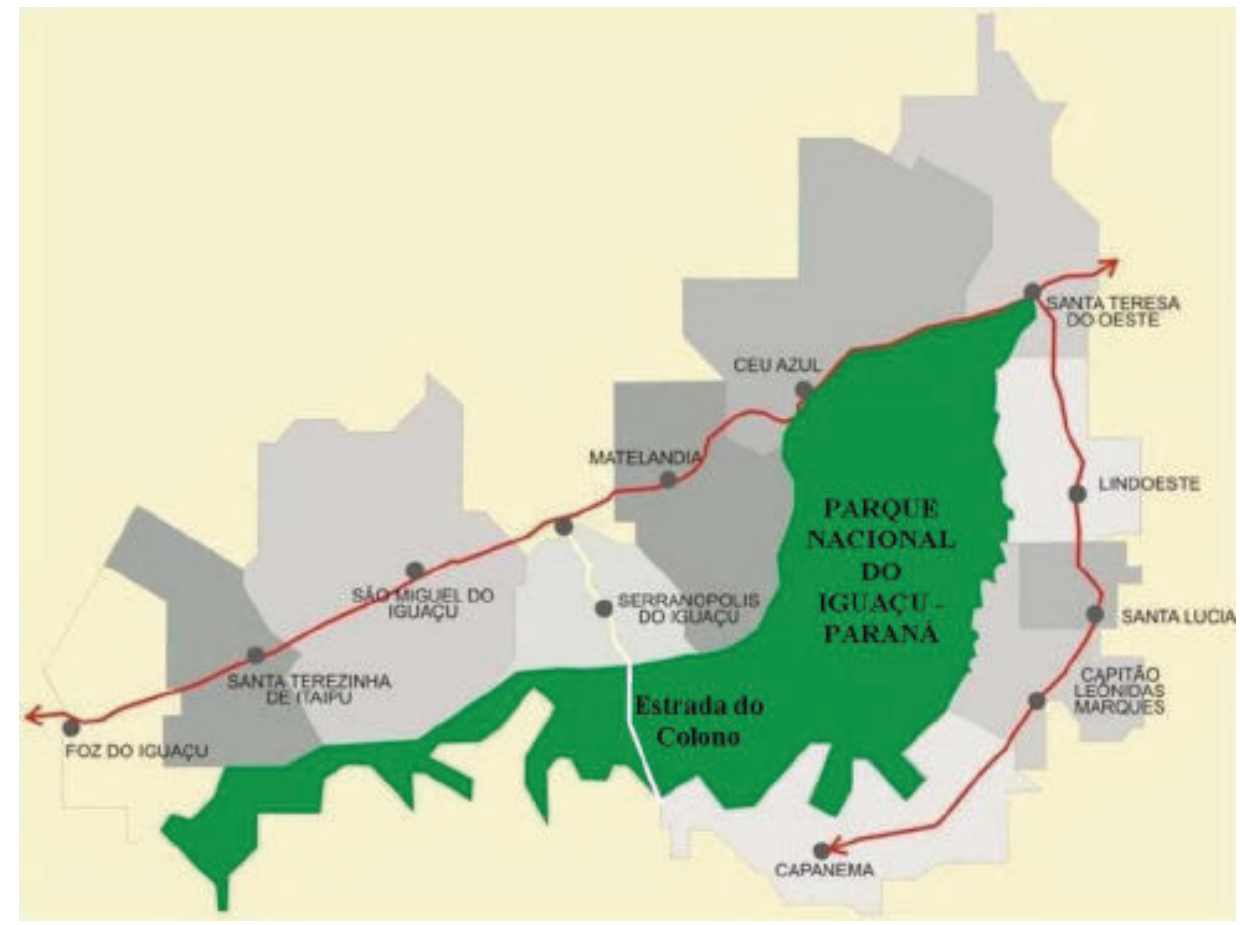

Figura 1. Ilustração do Parque Nacional do Iguaçu e sua área de influência - municípios do entorno Fonte: Administração do Parque Nacional do Iguaçu. Adaptado.

As entrevistas foram aplicadas a 22 proprietários rurais dos municípios de Capanema e de Serranópolis do Iguaçu, totalizando-se os beneficiários do PDTS nestes municípios, e nove entrevistas a outros atores sociais relacionados ao Programa, num total de 31 entrevistas, no período de abril a maio de 2009. No Quadro 1 estão descritas as três categorias de atores sociais incluídos na pesquisa, sua quantificação e localização: implementadores, articuladores locais e beneficiários.

Antes de proceder às entrevistas foram estabelecidos contatos por telefone com os representantes dos implementadores e articuladores locais, a fim de explicitar os objetivos da pesquisa e os procedimentos para o seu desenvolvimento, bem como para facilitar o acesso aos beneficiários, os quais representaram o maior grupo de entrevistados. Em ambos os municípios, foram feitas visitas preliminares às propriedades rurais, acompanhadas de representantes dos articuladores locais. Nesta ocasião, fazia-se o agendamento prévio para posterior realização da entrevista. Houve esclarecimento quanto às questões a serem formuladas e a importância de cada informação a ser solicitada. Informou-se sobre o uso de gravador para facilitar a coleta das informações e de que os entrevistados não seriam identificados na publicação dos resultados da pesquisa. Finalmente, instruiu-se a respeito da liberdade em participar ou não da entrevista e que, em caso positivo, haveria um termo que o entrevistado assinaria, formalizando seu consentimento livre e esclarecido. Cientes dos procedimentos, os que concordaram em participar assinaram o referido termo.

As entrevistas foram iniciadas com os beneficiários, seguidas dos articuladores locais e, finalmente, com os implementadores do PDTS. Estas últimas ocorreram no município de Foz do Iguaçu, onde é sediada a administração do Parque, e, uma delas, em Curitiba, com um representante da Ecoparaná. Em Foz do Iguaçu deu-se também continuidade ao levantamento documental.

Todas as entrevistas foram transcritas na íntegra. Os dados coletados com os implementadores e articuladores locais deram base à composição do histórico do PDTS e permitiram esclarecer pontos fundamentais referentes a ele, não encontrados nos documentos pesquisados. Estes dois grupos forneceram também informações que possibilitaram um melhor entendimento das questões que permeiam os depoimentos dos beneficiários, alvo principal desta da pesquisa. 
Quadro 1 - Classificação, descrição das categorias participantes e quantificação dos entrevistados

\begin{tabular}{|c|c|c|c|}
\hline GRUPO & ENTIDADES/ATIVIDADES ECONÔMICAS & LOCALIDADES & TOTAL \\
\hline Implementadores & $\begin{array}{l}\text { Colaboradores do Parque Nacional do Iguaçu e da Ecoparaná, parceiros na } \\
\text { idealização e implantação do Programa, totalizando cinco entrevistas. }\end{array}$ & $\begin{array}{l}\text { Foz do Iguaçu } \\
\text { Curitiba }\end{array}$ & 4 \\
\hline Articuladores locais & $\begin{array}{l}\text { Representantes das prefeituras municipais de Capanema e de Serranópolis } \\
\text { do Iguaçu e da Associação de Turismo Doce Iguassu de Capanema, parceiros } \\
\text { diretos dos implementadores e principal meio de contato com os beneficiários, } \\
\text { num total de quatro entrevistas. }\end{array}$ & $\begin{array}{l}\text { Capanema } \\
\text { Capanema } \\
\text { Serranópolis do } \\
\text { Iguaçu }\end{array}$ & $\begin{array}{l}1 \\
1 \\
2\end{array}$ \\
\hline Beneficiários & $\begin{array}{l}\text { Público alvo do PDTS - pessoas abrangidas diretamente pelas ações do } \\
\text { Programa, composto, em sua maioria, por produtores rurais com atividades } \\
\text { ligadas ao turismo - atividades produtivas (agroindústrias, produtores } \\
\text { orgânicos, orquidário e vinícola) ou de prestação de serviços (parque aquático, } \\
\text { pesque-pague, hospedagem, trilha ecológica, balneário, camping, esporte de } \\
\text { aventura, escola rural, fazenda hotel, museu), totalizando } 22 \text { entrevistados. }\end{array}$ & $\begin{array}{l}\text { Capanema } \\
\text { Capanema } \\
\text { Serranópolis do } \\
\text { Iguaçu } \\
\text { Serranópolis do } \\
\text { Iguaçu }\end{array}$ & $\begin{array}{l}5 \\
9 \\
3 \\
5\end{array}$ \\
\hline Total de entrevistados & & & 31 \\
\hline
\end{tabular}

Procedendo à análise de conteúdo, fez-se uma leitura exaustiva das entrevistas, a fim de se obter as categorias de análise que melhor desvendassem os dados necessários para os objetivos propostos neste estudo. De posse das categorias, foram extraídas subcategorias de análise, de acordo com os depoimentos. Estas, por sua vez, foram quantificadas e descritas individualmente. Cruzamentos entre subcategorias foram realizados para melhor compreender situações relevantes, de acordo com os objetivos formulados.

\section{RESULTADOS E DISCUSSÕES}

Como resultados decorrentes do PDTS foram abordadas as melhorias em termos de novas atividades, de rendimentos, de geração de emprego e novas ocupações e de mudanças na percepção dos beneficiários em relação às questões ambientais, mudanças na gestão e organização de suas propriedades, resultantes de ações por eles desenvolvidas para atender ao turismo rural, após sua adesão ao Programa.

\section{ATIVIDADES ABRANGIDAS PELO PDTS}

Em Serranópolis do Iguaçu oito propriedades rurais aderiram participação em atividades do que denominaram de roteiro de turismo rural, até então não consolidado e não divulgado como tal. No município de Capanema, por sua vez, doze proprietários rurais participavam de um roteiro com nível de organização mais destacado, na modalidade de associativismo, onde foi implantada uma associação paralela à formatação do roteiro de turismo rural Doce Iguassu, em 2005.

As atividades englobadas pelo PDTS estão quantificadas de forma detalhada na Tabela 1. A linha e a coluna em destaque refletem a situação das atividades desenvolvidas pelo público beneficiário do PDTS no momento da pesquisa, distribuídas por município e por subgrupo - produção ou serviço.

Observa-se que o PDTS incentivou o início de 12 (60\%) das 20 atividades econômicas existentes relacionadas ao turismo rural, nos dois municípios pesquisados. Destas, seis $(50 \%)$ fazem parte do Roteiro Doce Iguaçu, no município de Capanema, e seis (75\%) das atividades localizadas no município de Serranópolis do Iguaçu. Dentre essas 12 novas atividades, dez (83,33\%) se enquadram em prestação de serviços.

A maior proporção de novas atividades no município de Serranópolis do Iguaçu está relacionada ao fato de as ações para o turismo rural neste município terem sido iniciadas com o PDTS, 
enquanto que, em Capanema, metade das propriedades já tinha atividades voltadas a esse tipo de turismo, quando do início do Programa. Entre as novas atividades, cuja criação ou comercialização foram incentivadas pelo PDTS, estão agroindústrias, orquidário, balneários, fazenda hotel, camping, vinícola, pesque-pague e parques aquáticos.

Tabela 1 - Distribuição de atividades originadas antes e após o PDTS, por município e por subgrupo de beneficiários, no ano de 2009

\begin{tabular}{l|c|c|c|c|c}
\hline \multirow{2}{*}{ SUBCATEGORIAS } & \multirow{2}{*}{ TOTAL } & \multicolumn{2}{|c|}{ MUNICÍPIO } & \multicolumn{2}{c}{ SUBGRUPO } \\
\cline { 3 - 6 } & & Capanema & Serranópolis do Iguaçu & Produção & Serviço \\
\hline Início das atividades com o PDTS & $\mathbf{1 2 / 2 0}$ & $6 / 12$ & $6 / 8$ & $2 / 8$ & $10 / 12$ \\
\hline Atividades já existentes quando se iniciou o PDTS & $\mathbf{8 / 2 0}$ & $6 / 12$ & $2 / 8$ & $6 / 8$ & $2 / 12$ \\
\hline Total de atividades & $\mathbf{2 0 / 2 0}$ & $\mathbf{1 2 / 1 2}$ & $\mathbf{8 / 8}$ & $\mathbf{8 / 8}$ & $\mathbf{1 2 / 1 2}$ \\
\hline
\end{tabular}

O surgimento das novas atividades, bem como o fortalecimento das já existentes, condiz com resultados obtidos por Del Grossi e Graziano da Silva (2000) que destacam o crescimento do número das propriedades rurais pluriativas, sendo que prestação de serviços está entre as atividades não-agrícolas que mais crescem nas propriedades rurais.

\section{GERAÇÃO DE TRABALHO E RENDA}

A percepção dos beneficiários entrevistados quanto às vantagens econômicas mais específicas decorrentes da sua participação no PDTS refere-se à absorção da mão de obra dos familiares, além da geração de mais trabalho no campo e da melhoria da renda familiar. Conforme detalhado na Tabela 2, 13 de 20 (65\%) entrevistados destacaram a melhoria da renda familiar e 11 de 20 (55\%) enfatizaram a geração de empregos temporários e ocupação da mão de obra familiar. Tais mudanças criam condições materiais para reduzir a migração rural-urbana daqueles que não são absorvidos pelas atividades agrícolas.

Os informantes observaram que o trabalho temporário acontece principalmente na prestação de serviços, especialmente no verão, quando aumenta o fluxo dos visitantes.

Tabela 2 - Desempenho das atividades produtivas dos beneficiários do PDTS por total de atividades, nos municípios de Capanema e Serranópolis do Iguaçu, 2009

\begin{tabular}{l|c}
\hline \multicolumn{1}{c|}{ ITENS AVALIADOS } & FREQUÊNCIA \\
\hline Geração de emprego além da mão de obra familiar & $3 / 20$ \\
\hline Contratação de trabalho temporário & $8 / 20$ \\
\hline Melhoria da renda familiar & $13 / 20$ \\
\hline Ampliação da atividade após o PDTS & $4 / 20$ \\
\hline Total absoluto de atividades produtivas & $\mathbf{2 0 / 2 0}$ \\
\hline
\end{tabular}

\section{MUDANÇAS NA PERCEPÇÃO DAS QUESTÕES AMBIENTAIS, NA GESTÃO E NA ORGANIZAÇÃO DA PROPRIEDADE}

Mudanças da relação entre a comunidade e o parque, por intermédio das ações desenvolvidas pelo PDTS, de forma direta, ainda não foram registradas. As mudanças registradas por esta pesquisa restringem-se ao beneficiário e à sua propriedade, mas que, certamente, refletem na relação da comunidade com o Parque e criam condições para que se desencadeie um processo contínuo de mudanças conservacionistas. 
Nos seus depoimentos, os 22 beneficiários admitiram a ocorrência de mudanças na propriedade a partir das ações do PDTS, mudanças estas que representam, quase sempre, novas potencialidades para o desenvolvimento local. Na Tabela 3 estão indicados os tipos de mudança e a frequência em que ocorreram. São mudanças tangíveis como a maneira de gerir a propriedade, considerando aspectos ambientais (conservação dos recursos naturais, plantio de árvores e reciclagem de materiais), os aspectos estéticos e a limpeza ou higiene.

Tabela 3 - Mudanças admitidas pelos beneficiários, após ações do PDTS, nos municípios de Capanema e Serranópolis do Iguaçu, 2009.

\begin{tabular}{l|c}
\hline \multicolumn{1}{c|}{ MUDANÇAS } & BENEFICIÁRIOS \\
\hline Na organização/estética da propriedade & $08 / 22$ \\
\hline Na qualificação/ganho em conhecimento & $08 / 22$ \\
\hline Na gestão ambiental da propriedade & $04 / 22$ \\
\hline Na limpeza/higiene da propriedade & $04 / 22$ \\
\hline Nas relações sociais & $04 / 22$ \\
\hline Na paisagem original & $01 / 22$ \\
\hline Total absoluto de beneficiários & $\mathbf{2 2}$ \\
\hline
\end{tabular}

Vale destacar que houve também quem observasse alterações na paisagem original da propriedade e nos hábitos do proprietário como mudanças negativas resultantes do Programa. As mudanças dizem respeito a ajustes que tiveram de ser feitos para atrair e receber visitantes, provocando perturbação na vida do proprietário.

Como mudanças intangíveis, registram-se os ganhos de novos conhecimentos e melhoria nas relações sociais. Os que afirmaram obter mais conhecimentos referiram-se principalmente aos cursos e palestras ministrados, melhorando a qualificação pessoal e refletindo nas formas de lidar com o público e administrar a propriedade. A melhoria nas relações sociais dos participantes ocorre em função das ações desenvolvidas, como palestras, cursos, visitas técnicas em outras propriedades rurais e em outros municípios, recepção de grupos de visitantes, entre outras, como ilustram alguns dos seus depoimentos:

[...] a própria preservação [...] a reciclagem [...] o plantio de árvores, [...] preservação da fonte [...] Isso tudo a gente se interessou mais. Foi uma coisa [... que] a gente não pensava em fazer e depois a gente teve essa idéia (BENEFICIÁRIO 12C).

[...] a gente aprendeu muito [...]. A conservação de florestas... A higiene, de não deixar lixos ao redor da casa, do pátio, né (BENEFICIÁRIO 1S).

\section{PRÁTICAS CONSERVACIONISTAS}

Procurou-se investigar as práticas conservacionistas admitidas pelos beneficiários na tentativa de reduzir os aspectos ambientais negativos em suas propriedades (Tabela 4). Dez de 22 (45,45\%) afirmaram reflorestar a área. O plantio de árvores está diretamente relacionado com a recuperação da mata ciliar, com a destinação de área para a reserva legal, com o ajardinamento e com a produção de sombra na propriedade, ação esta incentivada para a melhoria do aspecto da propriedade para a recepção de visitantes, como ilustra o depoimento de um beneficiário:

A própria regeneração das matas ciliares também adveio com o turismo [...] Então, se hoje lá tem 50 metros abandonado, por exemplo, antes do turismo não tinha nenhum metro. Acontece que existe uma motivação, entendeu? (BENEFICIÁRIO 10C). 
Tabela 4 - Práticas conservacionistas adotadas pelos beneficiários, após ações do PDTS, nos municípios de Capanema e Serranópolis do Iguaçu, 2009.

\begin{tabular}{l|c}
\hline PRÁTICAS CONSERVACIONISTAS & BENEFICIÁRIOS \\
\hline Plantio de árvores & $10 / 22$ \\
\hline Destinação de rejeitos & $10 / 22$ \\
\hline Preocupação com uso dos insumos & $04 / 22$ \\
\hline Repressão à degradação ao meio ambiente & $03 / 22$ \\
\hline Práticas alternativas na agricultura & $03 / 22$ \\
\hline Total absoluto de beneficiários & $\mathbf{2 2}$ \\
\hline
\end{tabular}

Esta preocupação com o plantio de árvores tem sido verificada no município de Capanema devido à largura do rio Iguaçu que explica, em parte, tal interesse. Quanto ao município de Serranópolis do Iguaçu, a menor preocupação em reflorestar parece estar associada ao fato de ser este um dos únicos municípios do estado do Paraná a ter quase a totalidade de sua mata ciliar já recuperada, em conformidade com o que preconiza o Código Florestal.

A preocupação com a destinação dos rejeitos foi uma atitude também registrada. Nove dos dez (90\%), que manifestaram uma preocupação mais acentuada com a apresentação da propriedade, são do subgrupo prestação de serviços, o que pode explicar esta preocupação em função destas propriedades e dos serviços aí prestados se configurarem como o produto turístico em sim, objeto direto da demanda turística. Foram até registrados casos onde o beneficiário faz a separação dos lixos e vende para empresas de reciclagem, ou mesmo produzem o próprio adubo orgânico para ser utilizado na agricultura e jardinagem.

Há os que demonstraram preocupação quanto ao uso racional dos insumos, como água e energia elétrica, e compra de reciclados, preocupação esta que se relaciona com a redução de custos. Outros buscam desenvolver práticas alternativas na agricultura, principalmente no que se refere à redução no uso de agrotóxicos e fertilizantes químicos, e aplicação de técnicas de conservação do solo, como ilustram alguns depoimentos:

[...] nós buscamos sempre [...] a questão da conscientização no cuidar com os agrotóxicos [...] Sempre que possível utilizar roçadeira. E a gente faz a contenção também de erosão (BENEFICIÁRIO 2S).

[...] uso racional de tudo, tanto de adubos químicos, procuro sempre adubo natural [...] A parte de conservação de solo tenho todas elas implantada em toda minha propriedade; contenção de água de chuva [...] pra ser auto-suficiente em irrigação (BENEFICIÁRIO 7S).

Não estão aqui sendo considerados aqueles que sempre trabalharam com a produção orgânica, ou seja, os que trabalhavam com este tipo de produção anterior a qualquer ação do PDTS.

Existem também beneficiários que procuram combater a degradação ao meio ambiente e os impactos negativos causados por terceiros. Estes se limitam ao município de Capanema, onde a fiscalização do Parque, em parceria com o pelotão de Polícia Militar Ambiental, registra constantemente infrações ambientais relacionadas sobremaneira com a caça da fauna silvestre e a extração de palmito, tendo os caçadores acesso ao Parque por meio de embarcações utilizadas no rio Iguaçu. $\mathrm{O}$ aumento da frequência de pessoas (proprietários, colaboradores ou visitantes) nessas propriedades, tornando menos inóspitas as margens do Iguaçu, possibilita a inibição deste tipo de prática, conforme a percepção dos beneficiários:

[...] hoje o turismo, queira ou não queira, mas inibe caça, inibe extração de palmito, onde tem as propriedades, onde tem mais gente. É mais... visitada, é mais presente, né, na barranca do rio (BENEFICIÁRIO 9C). 
[...] antigamente lá existia uma grande pressão de pescadores na fazenda [...] Com a chegada do turismo [...] aquilo lá virou uma atividade empresarial [...] é feito através de um monitoramento hoje o acesso ao rio [...] (BENEFICIÁRIO 10C).

\section{PERCEPÇÃO SOBRE ÁREAS PROTEGIDAS}

Ao investigar a percepção dos beneficiários quanto à existência de áreas protegidas, observou-se que esta é positiva quando pensada em âmbito global, transcendendo os benefícios à região em que se localiza. No entanto, as restrições legais, ao limitarem os proprietários rurais localizados na área de influência, geram uma percepção negativa para alguns beneficiários, já que os "prejuízos" a eles tributados "bancam" os benefícios difusos gerados por estas áreas. Mesmo assim, de acordo com os objetivos do PDTS, houve comprometimento e interesse destas pessoas para com as ações previstas.

No que se refere à Estrada do Colono, motivo de conflitos históricos entre a UC e as comunidades do entorno, no geral, não se observaram ressentimentos por parte dos entrevistados e a própria administração do Parque acredita ser um conflito amenizado, tendo em vista que a Estrada permanece fechada, de acordo com o que preconiza o plano de manejo da UC.

\section{ADEQUAÇÕES AMBIENTAIS QUANTO AO CÓDIGO FLORESTAL}

Quanto às adequações ambientais das propriedades participantes do PDTS, referentes ao Código Florestal, as localizadas no município de Serranópolis do Iguaçu apresentaram melhores resultados: $75 \%$ das propriedades possuem reserva legal averbada e $86 \%$ apresentam a mata ciliar recuperada, contra $27 \%$ e $33 \%$, respectivamente, nas propriedades de Capanema. Vale destacar que as particularidades geográficas deste último afetam sobremaneira no aumento dos custos para recompor a mata ciliar. No entanto, a proporção de reserva legal exigida é a mesma para ambos: $20 \%$ da área total da propriedade.

Em função da falta de uma base de dados anterior ao PDTS, apontando o nível de conservação dos recursos naturais, esta pesquisa ficou impossibilitada de avaliar os resultados de conservação do Parque, decorrentes das ações do PDTS. Sabe-se, no entanto, que a melhoria na gestão das propriedades e a preocupação em adequá-las à legislação ambiental, incentivada pelo PDTS, pode refletir positivamente na conservação dos recursos naturais, não só das propriedades, mas também da UC.

\section{CONSIDERAÇÕES FINAIS}

Os dados obtidos não permitem estabelecer uma relação explícita e direta entre desenvolvimento local e gestão mais eficaz na conservação dos recursos naturais, particularmente no caso de uma unidade de conservação como é o Parque Nacional, mas é nítido o reconhecimento dos proprietários rurais na ampliação de atividades resultantes das ações do PDTS para expansão do turismo rural nos municípios estudados, seguida da ampliação de empregos ou ocupações temporárias não-agrícolas. Acompanhando os ganhos resultantes de novas atividades e novos empregos ou ocupações, foram identificadas mudanças na gestão da propriedade rural e adoção de novas práticas e novos hábitos, favoráveis à conservação dos recursos naturais, sem que se constatassem ressentimentos em função do conflito histórico com a antiga Estrada do Colono.

Esses resultados permitem supor que os ganhos e mudanças registradas, em favor das condições de vida na unidade familiar e na conservação dos recursos na propriedade, representam uma redução nos riscos da pressão antrópica sobre o Parque. Para que se possa concluir de forma mais contundente a respeito da relação entre desenvolvimento local e eficácia na gestão para a conservação, recomenda-se analisar não só as mudanças que acontecem na propriedade dos beneficiários 
do Programa desenvolvido, mas também o que acontece no interior do Parque, enquanto resultado dessas mudanças empreendidas pelos proprietários rurais.

\section{REFERÊNCIAS BIBLIOGRÁFICAS}

ARRUDA, R. S. V. Populações tradicionais e a proteção dos recursos naturais em unidades de conservação. Ambiente \& Sociedade, Campinas, ano II, n.5, p.79-93, 2o Semestre, 1999.

ARRUDA, R. S. V. Populações tradicionais e a proteção. In: DIEGUES, A. C. (org). Etonoconservação: novos rumos para a proteção da natureza nos trópicos. São Paulo: Hucitec, 2000.

BARDIN, L. Análise de conteúdo. Tradução: Luís Antero Reto e Augusto Pinheiro. Lisboa: Edições 70, 2007. BENSUSAN, N. Conservação da biodiversidade em áreas protegidas. Rio de Janeiro: Editora FGV, 2006. BORRINI-FEYERABEND, G., KOTHARI, A. OVIEDO, G. Indigenous and local communities and protected areas: towards equity and enhanced conservation. Gland, Switzerland e Cambridge: IUCN, 2004. CEBALLOS-LASCURÁIN, Héctor. Tourism, ecotourism, and protected áreas. In: IV World Congress on National Parks and Protected Areas: The state of nature-based tourism around the world and guidelines for its development, 4. 1996, Anais... Gland, Switzerland, and Cambridge, UK: IUCN - International Union for Conservation of Nature and Natural Resources, 1996. ISBN: 2-8317-0124-4.

DEL GROSS, M. E.; GRAZIANO DA SILVA, J.. Ocupações e rendas rurais no Brasil. In: ORNAS: ocupações rurais não-agrícolas. Londrina. Anais... Londrina: IAPAR, 2000.

DENKER, A. F. Métodos e técnicas de pesquisa em turismo. São Paulo: Futura, 2000.

DIEGUES, A.C. Etonoconservação: novos rumos para a proteção da natureza nos trópicos. São Paulo: Hucitec, 2000.

118 GOODWIN, H. Local community involvement in tourism around national parks: opportunities and constraints. Current Issues in Tourism, vol. 5, n. 3 \& 4, p. 338-360, Jun. 2002

HARTSHORN, G. Ecological basis for sustainaible development in tropical forests. Annual Review of Ecological Systems, v. 26, p. 155-75, 1995.

MINAYO, M. C. de S. O desafio do conhecimento: pesquisa qualitativa em saúde. São Paulo: Hucitec, 8. ed., 2004.

MMA, Ministério do Meio Ambiente. Política ambiental integrada para o desenvolvimento sustentável - relatório de gestão 2003 - 2006. Brasilia: MMA, 2007.

MORSELLO, C. Áreas protegidas públicas e privadas: seleção e manejo. São Paulo: Anablume, 2. ed., 2006.

MURRAY Li, T. Engaging simplifications: community-based resource management, market processes and state agendas in Upland Southeast Asia. World Development. vol. 30, n. 2, p. 265-283, 2002.

PÁDUA, J. P. A ocupação do território brasileiro e a conservação dos recursos naturais. In: Unidades de conservação: atualidades e tendências. Curitiba: Fundação O Boticário de Proteção à Natureza - Rede Nacional Pró Unidades de Conservação, 2004.

PIMBERT, M. P.; PRETTY, J. N. Parques, pessoas e profissionais: colocando participação no manejo de áreas protegidas. Trad. Antonio Carlos Diegues e Daniela Andrade, In: UICN. DUDLEY, N. (Editor). Directrices para la aplicación de las categorías de gestión de áreas protegidas. Gland, Suiza: UICN, 2008.

Trabalho enviado em novembro de 2011

Trabalho aceito em dezembro de 2011 